\title{
Editorial \\ Critical Debates and Developments in Child Protection: Some Introductory Comments
}

\author{
Nigel Parton (1) \\ School of Human and Health Sciences, University of Huddersfield, Huddersfield HD1 3DH, UK; \\ n.parton@hud.ac.uk
}

Received: 10 June 2020; Accepted: 10 June 2020; Published: 15 June 2020

I would like to begin by thanking all of the authors who have contributed to this Social Sciences Special on "critical debates and developments in child protection" for their hard work and timely dedication in responding so positively to the requests and timelines made of them. Additionally, I would like to thank the reviewers who work so tirelessly behind the scenes and who help insure that such high-quality articles are published. This Special Issue aimed to build on a previous Special Issue in Social Sciences in 2014- "Contemporary Developments in Child Protection".

The last 50 years have witnessed increasing public, political and media concern about the social problem of child maltreatment and what to do about it. This is now evident in most jurisdictions and is receiving serious attention from many international and transnational organisations. While the (re)discovery of the problem originally took place in the USA and was particularly associated with the "battered baby syndrome" (Kempe et al. 1962), the objects of concern have now expanded to include physical abuse, sexual abuse, neglect, emotional abuse, abuse on the internet, child trafficking, sexual exploitation, female genital mutilation, gang membership and radicalization and is seen to affect all children and young people and not just young babies. In the process, the focus of attention has widened from simply intra-familial abuse to abuse in a wide variety of extra-familial settings including schools, sports clubs, day care, the church and the wider community. There has also been a broadening of concern from not only protecting children from "serious harm" but also to preventing the impairment of their health and development and ensuring that they are able to grow up in circumstances that are consistent with the provision of effective care so that all children can achieve the best outcomes.

To reflect these changes, the laws, policies, practices and systems designed to identify and prevent child maltreatment have themselves become much more wide-ranging and complex and have been subject to regular review. Social workers, health and education workers, the police and other criminal justice workers, as well as members of the wider community, are now all seen to have key roles to play in both protecting children and young people and assessing and monitoring actual and potential perpetrators.

Increasingly, the efficacy and effectiveness of child protection policies, practices and systems have been subject to high-profile media and political scrutiny and critical social science analysis and research. It is clear that what we understand by child protection, together with the idea of child maltreatment itself, is shaped by a wide range of social, cultural and political factors and that this varies both over time and in different contexts (see, for example, Parton 1985, 2014, 2020).

The international nature of these challenges is reflected in the different countries represented in the papers published in this Special Issue, with authors based in Australia, Canada, England, Ireland, Kenya, New Zealand, Norway, South Africa, Spain and Switzerland.

The broad and diverse nature of the challenges for child protection are demonstrated by the range of topics addressed in these papers. Ben Matthews, Leah Bromfield and Kerryann Walsh compare official reports of child sexual and physical abuse in two Australian jurisdictions with different mandatory reporting laws, Victoria and Western Australia, paying particular attention to the impact of 
the introduction of a reporting duty for child sexual abuse in Western Australia. We have two papers concerned with child protection in sport: the paper by Daniel Rhind and Jamie McDermott reports on an investigation of a framework designed to safeguard children with a disability in Rugby Union called TACL (Trigger, Action Plan, Communicate, Learn), while Gretchen Kerr, Bruce Kidd and Peter Donnelly discuss the "struggle" to advance child protection in Canadian sport.

The article by Susan Young, Margaret McKenzie, Cecilie More, Liv Schjelderup and Shayne Walker reflects on the child rights and family inclusion provisions of the United Nations Convention on the Rights of the Child (UNCRoC) and the Aotearoa New Zealand Children, Young Persons and their Families Act (1989) as these apply to Aotearoa New Zealand, Norway and Western Australia. Sara Perez-Hernando and Nuria Fuentes-Pelaez provide a systematic review which analyses the conceptualisation of social support in order to create social support networks and the benefits of the intervention for families. The article by Eduard Vaquero, M Angels Balsells, Carmen Ponce, Aida Urrea and Alicia Navajas is also concerned with the benefits of social support but specifically for the biological family during the foster care process. The article by Caroline McGregor and Carmel Devaney discusses the challenges and possible obstacles of a framework which aims to inform "protective support and supportive protection" in child protection and welfare practice and supervision.

The article by Afrooz Kaviani and Julia Sloth-Nielson applies a child rights lens to safeguarding efforts in the aid sector with a focus on the least developed countries in Africa. It argues that child rights law can be leveraged to encourage the effective government oversight of NGOs in contact with children as part of national frameworks for child protection. Njeri Chege and Stephen Ucembe critically analyse what they call Kenya's "over-reliance" on institutionalisation as a childcare and child protection model for children deprived of parental care, which they argue requires a root-cause approach in order to provide alternative family-based care. Emily Keddell discusses the important justice implications of the increasing reliance on algorithmic tools in child protection decision-making, while Edgar Marthinsen, Graham Clifford, Halvor Fauske and Willy Lichtwarck argue that the increasing reliance on case management and overly rationalised procedures in child protection fails to take into account the needs of both families and children. The article reports on a piece of work to help practitioners challenge these developments and to enhance their knowledge of innovation in child protection. Lauren Elizabeth Wroe and Jenny Lloyd address a central tension at the core of social work in child protection-the need to develop relationships of trust and the practice of surveillance-in the context of extra-familial forms of harm. They discuss an analytic framework which they have developed in order to address these challenges and, in the light of applying this to two case studies, they identify the critical issues that should be considered in future work in this area.

Conflicts of Interest: The author declares no conflict of interest.

\section{References}

Kempe, Henry, Frederic Silverman, Brandt Steele, William Droegemueller, and Henry Silver. 1962. The Battered Child Syndrome. Journal of the American Medical Association 181: 17-24. [CrossRef] [PubMed]

Parton, Nigel. 1985. The Politics of Child Abuse. Basingstoke: Palgrave/Macmillan.

Parton, Nigel. 2014. The Politics of Child Protection: Contemporary Issues and Future Directions. Basingstoke: Palgrave/Macmillan.

Parton, Nigel. 2020. Addressing the Relatively Autonomous Relationship between Child Maltreatment and Child Protection Policies and Practices. International Journal on Child Maltreatment: Research, Policy and Practice 3: 19-34. [CrossRef]

(C) 2020 by the author. Licensee MDPI, Basel, Switzerland. This article is an open access article distributed under the terms and conditions of the Creative Commons Attribution (CC BY) license (http://creativecommons.org/licenses/by/4.0/). 